\title{
Public Health and the People's Health
}

\author{
By ERNEST M. GRUENBERG, M.D., Dr.P.H.
}

$\mathrm{P}$ UBLIC HEALTH is part of civilization's fight for a better life. With civilization comes an organized, conscious effort to change man's relation to his physical and social environment.

Civilization's fight against disease, specifically, seeks to cheat death for a brief space and to protect man from nonfatal diseases that produce illness. This is done by inventing specific ways of preventing disease. It is strengthened by a social movement to put these inventions to work on a broad scale. The specific public health movement, 100 years old, has created responsible armies of workers and organizations to see that existing inventions are applied and new inventions are made.

The three main forces affecting the level of a people's health are the natural hazards to survival and their distribution, the level of civilization, and the advance of public health.

The history of man's health, which still remains to be written, will describe what is known about the milleniums during which man was at the mercy of natural hazards with little understanding of what they were and with no effective means of acting against them.

Dr. Gruenberg, a member of the technical staff of the Milbank Memorial Fund, New York City, was executive director of the New York State Mental Health Commission from 1949 to 1954. A full version of this paper, here somewhat abridged, was delivered May 2, 1956, in Columbus, Ohio, at the joint meeting of the Middle States Public Health Association and the Ohio Public Health Association. States in the former group are Illinois, Indiana, Iowa, Kansas, Michigan, Minnesota, Missouri, Nebraska, North Dakota, Ohio, South Dakota, and Wisconsin.
The next great period will deal with advancing civilization and the increasing effect of technology on raising living standards and averting famines.

The past century accelerated the advance of public health. Simultaneous with the development of techniques for organized health campaigns, public health movements have become pandemic in Europe and North America. Knowledge has been increasing at a phenomenal rate, giving public health ever more powerful weapons. This new power will raise new responsibilities and require repeated self-examination regarding their nature.

In Ceylon, life expectancy at birth gained nearly a year per year for the 6 years beginning in 1947. A similar rapid rise in life expectancy occurred also in Japan and Puerto Rico while in some other areas, although more favorably situated, populations have not shown such dramatic changes (1).

One implication of these phenomenal successes is that whereas public health formerly represented a late stage in technical development, working effectively to supplement industrialization and to mitigate the harmful consequences of urbanization, new knowledge has made it so powerful that it can precede other forms of social progress.

Another implication is that, while advances in health have often served to assist the process of social development, public health never before had the power to create radically new patterns of disease and mortality, relatively unassisted by general rises in the level of living.

In some places health protection and promotion have become the chief instruments for producing rises in the level of living and in releasing uncounted millions of lives for productive labor. 
To the epidemiologist this means that the distribution of organized health movements has become the chief factor in understanding the distribution of many diseases and the pattern of human mortality.

\section{Charting the Future}

These and other signs of the power of organized public health are so much on our minds, and respect for its power to effect changes in the people's health is so widespread, that the whole movement seems to be circling in a moderately dazed way in an attempt to find suitable targets on which to strike.

There are dangers in this situation. An example is the mental health movement which, since the war, has come into its own. Although to the administrator popularity may be a matter of envy, to the serious worker it soon becomes a matter of concern.

There is a danger that we come to believe that such popularity must be deserved.

There is a danger that we come to believe our enthusiastic supporters when they claim that we are capable of anything.

There is a danger that we allow ourselves to be held responsible for things we cannot do.

In a time when our power has increased we must remember our duty to inform the public of the sober realities of their health situation. Public health workers have always been long on faith and enthusiasm and at times short on facts and self-criticism. With the powerful weapons that are now available and the widespread faith and enthusiasm that are evident, the movement needs to strengthen its balance wheel of facts and self-criticism.

The suggestion that the next great chapter in public health should be centered on positive health and medical care can be misleading.

Medical care has become a powerful tool for reducing disability and postponing death in the presence of certain diseases. Furthermore, everyone has the right to expect the best available medical care when he is ill.

But, from the public health point of view, every case that comes to medical care represents a failure of a movement whose objective is to keep illness from occurring. Obviously, physicians in this country keep very busy in spite of preventive medicine's great successes. Public health will not be doing its job unless it tackles the causes of morbidity and mortality which still plague the people.

\section{Attacking Preventable Diseases}

First, we must do what we know how to do. There are some vital gaps in civilization's battle against disease.

Wre have not found practicable ways of preventing all preventable diseases, diseases for which the technical means of prevention are well established. The great progress on which we compliment ourselves has affected a pitifully small percentage of the world's population. Malaria alone, a completely preventable disease, is still a great killer.

It is not only abroad that these gaps are to be found. Malnutrition, tuberculosis, venereal disease, excess infant and maternal mortality, and inadequate medical care and rehabilitation are often found in the United States in particular neighborhoods and sections of the population. Infant mortality in New York City, for example, is as high as 35 per 1,000 live births in 4 districts and as low as 17 in some districts of the city (2).

Retarded populations in this country suffer not only from poor health but also from poverty or ignorance. If public health is going to continue to work for the improvement of the people's health, it will concentrate on these populations.

One useful approach is the examination of patterns of differential mortality rates. Although we are working toward consistency and constancy in statistics on occupation and mortality, England has issued tabulations of mortality by social classes for several generations. While we have failed, perhaps, to be impressed by the fact that the standardized mortality ratio for the least favored populations in England and Wales is twice as high as for the most favored, we should be impressed by the fact that age-specific death rates for adult males are higher for each comparable age group in this country than in England. And we should be even more impressed by the fact that standardized mortality ratios vary more by occupational groups in this country than in England (3). 
This is not the place to recommend solutions. It is important to recognize that these problems exist and that the measures available point unmistakably to unfinished business for public health.

Some of the specific areas for attention which might lead to a reduction of some of these differentials are well known. To list a few :

- Nutrition is not optimal for the entire population.

- Housing is not sanitary or safe for all.

- Fluoridated water is not yet available to most urban families.

- Medical care is not readily available to those who need it most. In particular, the aged frequently cannot afford the high costs of medical and nursing care. Often they do not receive the detailed attention that medical science can offer to preserve remaining functions.

Dr. Haven Emerson once propounded the theorem that the first step in public health occurred when man rose up out of his own filth. Although mankind has long since passed that early stage, it now finds itself surrounded by man's collective filth in air and water. 'The present movement to rid rivers, coasts, and city air of man-made pollution has scored some signal successes on a few small fronts. The staggering proportions of the problem and its implications for civilized life illustrate the old proposition that public health cannot "go it alone" but must act as a center of technical and community leadership for all the forces interested in the people's health and welfare.

\section{Using Knowledge Fully}

There are also some new frontiers for public health. Four major health problems-mental diseases, arteriosclerosis, cancer, and the common cold-serve to remind us that there are still diseases we do not know how to control and that there are some public health objectives we would like to reach but do not know how.

A proper humility before the forces of nature obliges us to recognize that we are powerless to prevent these conditions in the mass and that medical science can do little to change the course of most of these diseases once they are started on their way.

Our first obligation as professional health workers is to know the facts. Our second is to communicate them intelligibly to the people we serve. Our third is to devise and execute schemes to put the limited knowledge we do have to effective use.

For example, though many prevention programs have been instituted in the mental diseases, most have ignored established knowledge.

In one State the mental health program is centered on human relations in the health department and in the schools. Some cases of pellagra psychosis occur each year, but the program does not consider control of these preventable cases to be its function. Nor does it concern itself with the preventable cases of neonatal brain hemorrhage caused by $R h$ incompatibility. Available knowledge strongly suggests that young infants and preschool children require stable family life for healthy personality development, but the program does not seek to prevent preschool children from being housed and fed in institutions or in a series of foster homes.

It would seem that the first item on any public health program must be the elimination of preventable instances of morbidity and mortality. But the bulk of mental illness today cannot be prevented by known techniques.

Can we shorten the duration of some mental cases? There is some reason for hope in this direction. Acute depressions in the involutional years are sensitive to shock treatments. Some neuroses of childhood seem to be relieved by quick responses by the adults in the child's environment. Mental deficiency is partly treatable.

Can we reduce the disability which mental illness produces? In many instances, yes. We know that we overhospitalize mental illnesses in a wanton fashion. We know that with good medical care many chronically ill people can live slightly impaired lives instead of hospitalized lives.

Programs which emphasize positive mental health often distract attention from the pluses and minuses in our knowledge. Mental health programs emphasize child guidance clinics, but the clinics generally prefer to see chronic neuroses rather than to try to see an acute neurosis while it is acute or to help a neglected infant. Programs emphasize building more hospitals 
when the use of mental hospitals has become excessive. Psychiatrists are trained to treat the least ill rather than the chronically ill whose disability they could often reduce. Education programs are called preventive even when there is no real reason for believing they have any important preventive effects.

\section{Avoiding Illusions}

Parent education is necessary within reason, and child guidance clinics, adult psychiatric clinics, mental hospitals, psychotherapy for neuroses are both necessary and valuable. Perhaps the emphasis on these activities in existing mental health programs comes from an illusory kind of thinking. Some of these illusions have become our standard ways of avoiding unpleasant realities. 'To describe a few :

"Where there is a will, there is a way." This is true about carrying out an activity, but it is not true about achieving an objective. You may shout across the ocean with great will, but without a radio you will not be heard. You may educate parents with gusto, but you cannot be sure you have prevented any mental disease.

"Early diagnosis and treatment is secondary prevention because it shortens disease or reduces disability." This is a simple inversion of the true proposition that secondary prevention consists of early diagnosis and effective treatment. Ineffective treatment doesn't help arteriosclerosis. There is no real reason to think that early diagnosis and treatment can reduce morbidity or mortality in this disease.

"Activity is good." It isn't always.

"If one clinic doesn't help, get two." If one super anticold pill doesn't stop your cold, take two. If two don't help, take three.

"Doctrine of signs and names." This illusion consists of the belief that the name of an agency describes its effects. To stop the common cold, set up an anticold commission and give it the assignment of stopping colds. If the incidence of colds goes up the first year, enlarge the agency the second. After staff has obtained tenure and the rates are still rising, have a shakeup, change the name, and bring in a director who has impressive qualifications. The chances are that you will get a competent staff who think the common cold is a bad thing, who will probably find ways of reducing the amount of headaches and coryza, who may produce some skin-tanned children by lighting classrooms with ultraviolet lights, and who will increase the sale of nasal paper tissues, and decrease the sale of pocket handkerchiefs. They will keep busy and do some useful things, but they probably won't have much effect on the number of people who suffer from the common cold.

The reason is obvious: They don't have the knowledge; they don't have the techniques. In spite of good scientific training in tailoring means to fit ends and in learning to recognize facts as facts, the best intentioned of us get carried away by the desire to effect changes, to slay the wicked dragons. When ignorance or difficulties frustrate, we switch goals and develop formulas for self-justification.

These are some of the current thoughts of one mental health worker regarding the future of public health. The objective of public health work is to control disease. The value of public health activity depends entirely on its success in achieving that objective. As techniques become more powerful and as health organizations become larger, the responsibility for keeping track of our successes and failures becomes greater.

The successes of the past can guide us, but the successes of the future will be even greater and will demand as much originality and steadfastness from public health workers.

The people's health is becoming increasingly more subject to the control of public health, but the people's health still manages to vary in ways which public health has not yet been able to control.

\section{REFERENCES}

(1) Stolnitz, G. J.: Comparison between some recent mortality trends in underdereloped areas and historical trends in the West. In Trends and differentials in mortality. New York, Milbank Memorial Fund, 1956, pp. 26-34.

(2) New York City Health Department: Summary of vital statistics, 1955. New York City, The Department, 1956.

(3) Moriyama, I. M., and Guralnick, L.: Occupational and social class differences in mortality. In Trends and differentials in mortality. New York, Milbank Memorial Fund, 1956, pp. 61-73. 